\title{
Future impact of anthropogenic sulfate aerosol on North Atlantic climate
}

\author{
Irene Fischer-Bruns · Dorothea F. Banse • \\ Johann Feichter
}

Received: 28 September 2007 / Accepted: 14 August 2008/Published online: 16 September 2008

(c) The Author(s) 2008. This article is published with open access at Springerlink.com

\begin{abstract}
We examine the simulated future change of the North Atlantic winter climate influenced by anthropogenic greenhouses gases and sulfate aerosol. Two simulations performed with the climate model ECHAM4/OPYC3 are investigated: a simulation forced by greenhouse gases and a simulation forced by greenhouse gases and sulfate aerosol. Only the direct aerosol effect on the clear-sky radiative fluxes is considered. The sulfate aerosol has a significant impact on temperature, radiative quantities, precipitation and atmospheric dynamics. Generally, we find a similar, but weaker future climate response if sulfate aerosol is considered additionally. Due to the induced negative topof-the-atmosphere radiative forcing, the future warming is attenuated. We find no significant future trends in North Atlantic Oscillation (NAO) index in both simulations. However, the aerosol seems to have a balancing effect on the occurence of extreme NAO events. The simulated correlation patterns of the NAO index with temperature and precipitation, respectively, agree well with observations up to the present. The extent of the regions influenced by the NAO tends to be reduced under strong greenhouse gas forcing. If sulfate is included and the warming is smaller, this tendency is reversed. Also, the future decrease in baroclinicity is smaller due to the aerosols' cooling effect and the poleward shift in track density is partly offset. Our findings imply that in simulations where aerosol cooling is neglected, the magnitude of the future warming
\end{abstract}

I. Fischer-Bruns $(\square) \cdot$ D. F. Banse $\cdot$ J. Feichter

Max Planck Institute for Meteorology, Bundesstrasse 53,

20146 Hamburg, Germany

e-mail: irene.fischer-bruns@zmaw.de

\section{F. Banse}

International Max Planck Research School on Earth System Modelling, Bundesstrasse 53, 20146 Hamburg, Germany over the North Atlantic region is overestimated, and correlation patterns differ from those based on the future simulation including aerosols.

Keywords Sulfate aerosol - Direct aerosol effect . Climate change $\cdot$ North Atlantic cyclones $\cdot$ NAO

\section{Introduction}

The increase of anthropogenic greenhouse gases in the earth's atmosphere is the main forcing responsible for the global warming expected for the next decades. On the other hand, aerosols as forcing agents of climate change are known to be important, as shown by analyses of satellitebased measurements, e.g. regarding the clear-sky direct radiative forcing (e.g. Bellouin et al. 2005). Since aerosols experience a large temporal and spatial variability, they are considered as one of the largest sources of uncertainty in climate projections. Their typical lifetime in the atmosphere is on the order of several days and depends strongly on their physical and chemical characteristics as well as the frequency of precipitation events. One key aerosol is sulfate of anthropogenic origin, the only one considered in this model study. Sulfate $\left(\mathrm{SO}_{4}\right)$ is an oxidation product of sulfur dioxide $\left(\mathrm{SO}_{2}\right)$ and a good indicator of industrial pollution. Sulfur dioxide is emitted mainly by fossil fuel burning, which accounts for about $72 \%$ of the total emissions (anthropogenic and natural), whereas biomass burning contributes only about $2 \%$ (Forster et al. 2007). It is oxidized to sulfuric acid gas, which condenses quickly on existing particles or forms new sulfate particles. The radiative forcing due to the sulfate aerosol's backscattering of sunlight is known to modify the anthropogenic greenhouse effect significantly, namely to oppose global 
warming. This fact has been demonstrated by introducing sulfate aerosol into climate models (e.g. Mitchell and Johns 1997; Reader and Boer 1998; Carnell and Senior 1998; Roeckner et al. 1999). As $\mathrm{SO}_{2}$ emissions have harmful impacts on human health and natural environment, as they cause for instance acid rain, many developed countries have been reducing these emissions from power stations. Thus it can be anticipated that this compensating effect will be weaker in the future.

The effects of sulfate aerosol may be separated into the 'direct effect' in regions without clouds and 'indirect effects' in cloudy regions. The direct aerosol effect on climate is due to scattering and absorption of sunlight. In case of scattering particles, the amount of sunlight that reaches the earth's surface is reduced due to the presence of the aerosol. Indirect effects are, for instance, the influence of the aerosol particles on cloud microphysical properties, such as reflectivity, lifetime and precipitation rates. An evaluation of the indirect effects and their consequences is beyond the scope of this paper. In this study, we concentrate on the possible future climatic changes in the North Atlantic region with special emphasis on the direct radiative impact of sulfate aerosol from anthropogenic origin. The direct aerosol forcing represents only a part of the overall aerosol effect; therefore our work represents also only a part of the entire picture of the aerosol's role in our climate. We investigate a simulation forced by greenhouse gases and a simulation forced by both greenhouse gases and sulfate aerosol. Ulbrich and Christoph (1999) and Knippertz et al. (2000) also analyzed the same simulation forced by greenhouse gases used in this study with respect to NAO and cyclone tracks. However, these studies do not take into account the additional effects of sulfate aerosol. To our knowledge, such an isolation of the aerosol forcing effects on the climate change in a specific region has not been attempted previously.

Details about the model and a description of the experimental design are given in Sect. 2. In Sect. 3, we describe the method to calculate the aerosol effect, our significance test and the cyclone tracking method. Section 4 presents the results for the direct aerosol effect upon temperature, radiative quantities, precipitation, NAO, baroclinicity and cyclone track density. The paper is summarized and concluded in Sect. 5.

\section{Model description and simulations}

\subsection{The climate model}

We analyze data of two transient model simulations performed with the ECHAM4/OPYC3 coupled atmosphereocean general circulation model (AOGCM) of the Max
Planck Institute for Meteorology (MPI-M, Roeckner et al. 1999). It consists of the atmospheric component ECHAM4, a spectral transform model at T42 resolution employing 19 vertical levels, and the oceanic component OPYC3 (an updated version of the OPYC model developed by Oberhuber 1993), which uses isopycnal coordinates at 11 vertical levels. Both model components are coupled quasisynchronously, exchanging daily averaged quantities once a day. The mixed layer temperature and the sea-ice variables are received by the atmospheric component without any adjustment. For the oceanic component solar radiation, river discharge, wind stress, and friction velocity are passed without adjustments as well. Restricted to heat and freshwater only, non-seasonal constant flux adjustments were employed to prevent the model from drifting to an unrealistic climate state. The adjustments were estimated from a 100-year coupled model spin up. Details on the coupling technique can be found in Bacher et al. (1998).

ECHAM4/OPYC3 is an AOGCM that has been used in climate modeling studies by several research groups worldwide. Work published earlier evaluated the performance of the atmospheric model and the coupled model (e.g. Roeckner et al. 1996a, b; Bacher et al. 1998; Roeckner et al. 1999). Despite the restriction of the flux correction to heat and freshwater only, the annual and seasonal climate of the coupled model agrees well with that produced by the atmospheric model component alone, when it is forced with observed sea surface temperatures (SSTs). The coupled model captures many features of the observed interannual SST variability in the tropical Pacific, mainly related to El Niño events. The results of the AOGCM show also adequate agreement with observations regarding the weakening of the westerlies across the North Atlantic in El Niño/Southern Oscillation (ENSO) winters, as well as regarding the weak tendency for colder than normal winters in Europe. Stephenson and Pavan (2003) compared the NAO simulated by the coupled model to observed data together with the results of 16 other AOGCMs (see Sect. 4.5). Comparisons of modeled data with reanalysis data and observations that are made for this study will be shown in Sects. 4.5-4.7.

\subsection{Simulations}

We investigate two transient climate simulations (Roeckner et al. 1999). One of the simulations is forced with time-dependent anthropogenic greenhouse gases alone (referred to as simulation GHG in the following). The second simulation additionally includes the backscattering of solar radiation due to the presence of sulfate aerosol originating from anthropogenic sulfur emissions (GSD). Natural biogenic and volcanic sulfur emissions are neglected. The GHG simulation has been performed for the 
period (1860-2100), the GSD simulation for (1860-2050). Since GSD is available only until 2050, we do not consider the last 50 years of GHG. The simulations allow for a separation of the aerosol effect from the anthropogenic greenhouse effect by building differences between the variables of both data sets (see Sect. 3.1). A third simulation (GSDIO), which has also been published by Roeckner et al. (1999), accounts for the influences of greenhouse gases, and additionally, ozone and considers both the direct and the indirect sulfate aerosol effects. The reason why the GSDIO simulation is not evaluated here is that a separation of the anthropogenic greenhouse gas effect and the aerosol effect would be impeded by the consideration of ozone.

In the simulations GHG and GSD, changes in concentrations of the major greenhouse gases $\left(\mathrm{CO}_{2}, \mathrm{CH}_{4}\right.$, $\mathrm{N}_{2} \mathrm{O}$ and certain halocarbons) are prescribed from 1860 to 1990 as observed. From 1991 to 2050 these concentrations are assumed as projected into the future according to the IPCC IS92a forcing scenario (Houghton et al. 1992). In simulation GSD the tropospheric sulfur cycle is fully coupled with the meteorology of the atmospheric component ECHAM4 (Feichter et al. 1996, 1997). The sulfate mass mixing ratio computed by the model is transformed into particle number concentrations under the assumption of a log-normal size distribution. The wavelength dependent optical properties are determined according to Mie Theory. Transport and deposition processes are calculated interactively. The simulated trend in sulfate deposition in GSD since the end of the nineteenth century is broadly consistent with ice core measurements (Roeckner et al. 1999). The assumed future emission of sulfur dioxide, also based on scenario IS92a, is higher than those for the six SRES emission scenarios (Nakicenovic and Swart 2000). The reason is that due to local air quality concerns in the industrialized countries, scenarios published since 1995 assume sulfur controls of different degrees for the future. This fact had not been considered at that time when the IS92a scenario was designed. The projected future increase in $\mathrm{SO}_{2}$ emissions by the developing countries is clearly visible in our simulations in a shift in sulfate burden towards the equator, as will be shown in Sect. 4.1.

The control simulation (CTL) is integrated over 300 years and is driven with constant 'present-day' greenhouse gas concentrations fixed at the observed 1990 values (IPCC 1990). Industrial gases (like halocarbons and others) are not considered. The prescribed concentrations of aerosols and ozone are based on climatologies. There is no sulfur cycle in this simulation. The CTL simulation is used for comparisons with reanalysis data and for a nonparametric significance test, which is described in Sect. 3.2. For more details on the model and the simulations we refer to Roeckner et al. (1999).

\section{Methods}

\subsection{Separating the aerosol effect}

In order to separate the aerosol effect on different variables, we calculate differences between the GSD and the GHG simulation of 30-year averages of these variables. Our analysis is restricted to a domain, which is limited to the North Atlantic Ocean and surrounding land regions $\left(90^{\circ} \mathrm{W}-60^{\circ} \mathrm{E}, 20-80^{\circ} \mathrm{N}\right)$. Regions in this domain that show significant differences are rather small for 'present periods' like (1961-1990) and the influence of the aerosol turns out to be largest in a warmer climate. Thus we focus only on the future climate and discuss mainly results for (20212050). Although photochemistry is more vivid in summer and hence the oxidation of sulfur dioxide yields a larger amount of sulfate in summer than in winter, we only consider boreal winter. The reason is that we are interested particularly in the NAO and the related North Atlantic storm tracks, and, in general, the winter exhibits most intense extra-tropical storms. During the winter season, the NAO accounts for more than one-third of the total variance in sea level pressure (SLP) over the North Atlantic region (Hurrell et al. 2003). In the following, the year corresponds to January for each winter season.

\subsection{Significance testing}

A widely used test for the comparison of two means is the Student's $t$ test. Apart from the distributional assumptions, this test requires that the data samples are statistically independent. This assumption is mostly violated in climatological applications since the data are serially correlated (Zwiers and von Storch 1995). In the following we do not address the problem of serial correlation. However, the Student's $t$ test should only be applied to data, which can be assumed as normally distributed and exhibiting comparable variances. In order to avoid these assumptions, we introduce a non-parametric significance test. Taking the future temperature difference as an example, our null hypothesis is: the difference (GSD-GHG) of the temperature averaged over (2021-2050) lies within the range of the variations of differences of temperature averages over 30-year periods, which are randomly chosen from the undisturbed CTL simulation. This hypothesis is tested against the alternative hypothesis that (GSD-GHG) exceeds this range: First we determine $m 30$ year-averages from the CTL simulation (here $m=10$ ) and subtract all these averages from each other. The frequency distribution of the $[m(m-1) / 2]=45$ differences is believed to represent an unbiased and robust estimation of the true distribution. Finally, we have to determine whether the difference (GSD-GHG) for (20212050) is located 'sufficiently far away' in the tail of this 
distribution. If it is larger than e.g. the $95 \%$ percentile, we can be $95 \%$ certain that the difference is statistically significant. In other words, the null hypothesis can be rejected with a risk of less than $5 \%$. We have tested the significance of all calculated differences (GSD-GHG) of variables averaged over (2021-2050) in this study with this method. The test has been performed at every grid point within our model domain. The colored areas of Figs. 2, 3 and 10 show regions with statistically significant differences at the $95 \%$ level. Regions with no significant differences are masked out and white-colored.

\subsection{Cyclone tracking}

In this study, we use the feature tracking algorithm proposed by Hodges (1999). Before identifying the mean sea level pressure (MSLP) minima in a data set with this method, it is recommended to remove wave numbers $\leq 5$ from the MSLP field. The reason is that there is uncertainty whether a low pressure system like the Icelandic low is formed by the successive movement of cyclones into the region or whether it is a feature of the planetary-scale background wave pattern. The removal of the planetary-scale background accommodates both views (Hoskins and Hodges 2002). The algorithm tracks the MSLP minima in time by minimizing a cost function which poses constraints on the upper displacement distance and the track smoothness to obtain the minimal set of smoothest tracks. In order to be detected, a cyclone has to exist at least for 2 days and has to travel a distance of at least $1,000 \mathrm{~km}$. The track density is defined as the number of tracks passing through a unit area defined as a circle of $5^{\circ}$ radius $\left(\sim 10^{6} \mathrm{~km}^{2}\right)$ per winter.

\section{Direct aerosol effect upon North Atlantic winter climate}

\subsection{Sulfate aerosol burden}

Figure 1 shows a picture of the future growth and shift in sulfate aerosol burden in extended boreal winter (DJFM) calculated in the GSD simulation according to the emissions of sulfur dioxide projected in the IS92a scenario. There is a strong increase in sulfate burden from "presentday' values (1961-1990) to the future period (2021-2050) (Fig. 1a, b). Due to the non-uniform distribution of sources, the spatial distribution of the aerosol burden is also rather inhomogeneous. The source regions are clearly identified by the darker colored areas. The mean burden is highest in source regions and downstream of them. The difference in burden between the averages over both periods (Fig. 1c) indicates a clear shift to the south. This shift is even more obvious on the global scale (not shown). It is due to the projected future decrease of $\mathrm{SO}_{2}$ emissions in the industrial countries and the future increase in the developing countries.

\subsection{Temperature, surface albedo and short wave radiation}

The sulfate aerosol effect on the near surface winter temperature for (2021-2050) is displayed in Fig. 2a, showing the difference (GSD-GHG) between both simulations. Since the aerosol backscatters sunlight, this leads to a cooling of the surface. Thus, the future temperature increase due to the increase in anthropogenic greenhouse gases is smaller in simulation GSD relative to GHG. Averaged over the whole region, the 'cooling', which is actually an attenuation of the warming, amounts to $-1.2^{\circ} \mathrm{K}$. There is no significant impact on temperature over the Labrador Sea and over Greenland, where the aerosol burden is lowest. Due to the slower decrease in sea ice and snow cover in the GSD simulation compared to GHG (Roeckner et al. 1999), the decrease in the future mean surface albedo is attenuated (Fig. 2b), which is indicated by positive values for (GSD-GHG). This happens over the Arctic Ocean, where the albedo difference is largest (up to $30 \%$ ), over some regions in northeastern Canada and northeastern Europe. As for temperature, no significant impact on the mean surface albedo of Greenland is found. Both the albedo effect and the aerosol backscattering effect imply a smaller increase in net short wave (SW) clear-sky (a) (1961-1990)

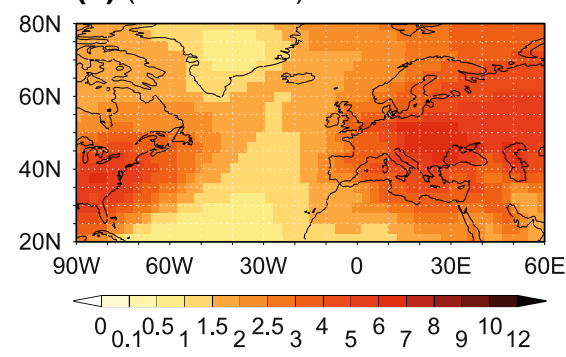

(b) (2021-2050)

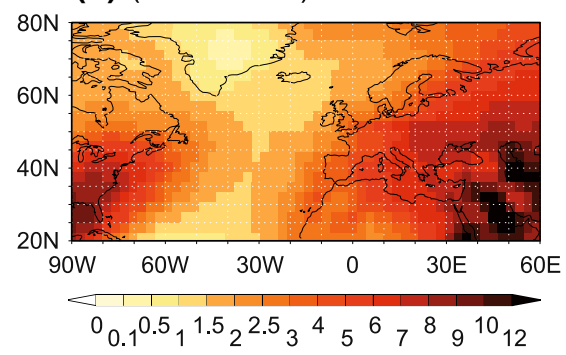

(c) (2021-2050)-(1961-1990)



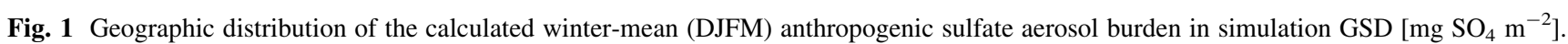
a Average over period (1961-1990), b average over period (2021-2050) and c difference between both multi-decadal averages 
(a) Near surface temperature

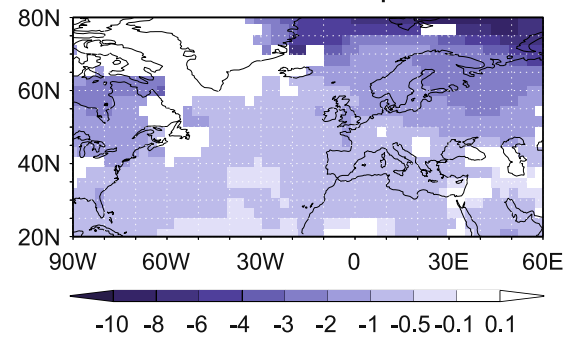

(b) Surface albedo

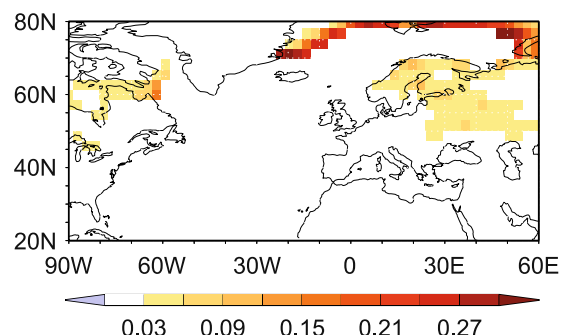

(c) Net SW radiation TOA

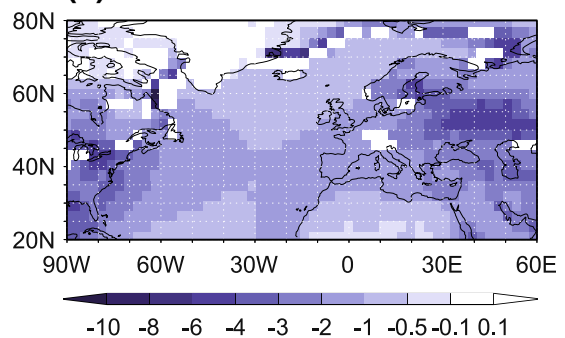

Fig. 2 Difference (GSD-GHG) of averages over (2021-2050) between both simulations of the winter-mean (DJFM) a near surface temperature $[\mathrm{K}]$, b surface albedo [dimensionless units] and $\mathbf{c}$ TOA

radiation in the GSD simulation over most regions, again with the exception of Greenland. This holds for the top-ofthe-atmosphere (TOA, Fig. 2c) as well as for the surface (SFC, not shown). The patterns for TOA and SFC net SW radiation compare well with each other, since-unlike the radiative impact of the greenhouse gases-the radiative forcing of the aerosol is changing the heat budget mainly at the earth's surface and not that of the atmosphere (Roeckner et al. 1999). Regions with the largest negative differences (GSD-GHG) in TOA net SW radiation coincide approximately with regions with the largest positive differences in surface albedo.

\subsection{Long wave radiation}

We also diagnose a weakened increase in the amount of outgoing long wave radiation (OLR) emitted to space in the GSD simulation compared to GHG for (2021-2050) (Fig. 3a). This variable depends strongly on the SFC net long wave (LW) radiation (not shown), which is balanced by two radiative fluxes with opposite sign: the upward infrared flux due to the LW earth's surface emission and the downward infrared flux emitted by the atmosphere due to the greenhouse effect. According to Raval and Ramanathan (1989) the latter is defined by the difference between the OLR and the surface LW emission. Since the anthropogenic greenhouse gas concentrations are equal in net shortwave clear-sky radiation $\left[\mathrm{Wm}^{-2}\right]$. Areas where the difference is not statistically significant at the $95 \%$ level are masked white

both simulations, we conclude that the aerosol impact on the greenhouse effect between both simulations is mainly due to the weakened increase in atmospheric temperature and water vapor concentration. As the air in the GHG simulation is warmer than in GSD, it can sustain higher concentrations of water vapor without becoming saturated. Consequently, more evaporation takes place and the concentration of water vapor may increase further. This in turn enhances the greenhouse effect and gives rise to further warming. The aerosol impact on the greenhouse effect for (2021-2050), shown in terms of LW radiation absorbed in the atmosphere, results in a weakening of this effect over large regions (Fig. 3b). However, the highly non-linear surface emission effect is clearly larger than the water vapor feedback (Roeckner et al. 1999), and the greenhouse effect is approximately proportional to the near surface temperature. This becomes evident by a comparison of Fig. $3 b$ with the temperature difference pattern (Fig. 2a).

\subsection{Precipitation}

If we consider only the increasing anthropogenic greenhouse gases (as in GHG) we find a poleward displacement of the mean winter precipitation pattern for (2021-2050) compared to the present (not shown). The associated precipitation increase at higher latitudes is related to an increase in water vapor in the atmosphere arising from the (a) OLR

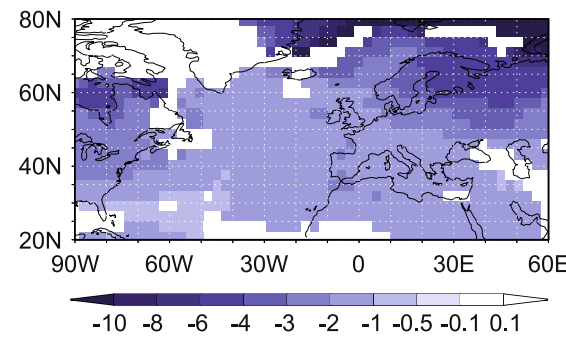

(b) LW radiation ATM

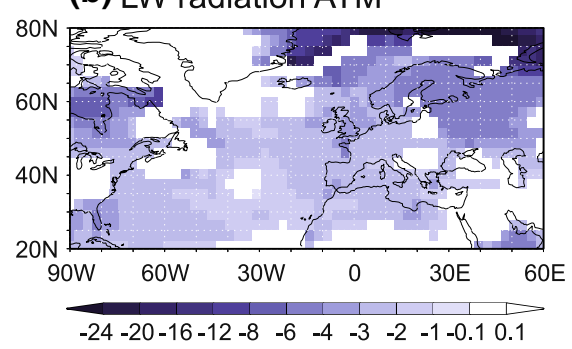

(c) Precipitation

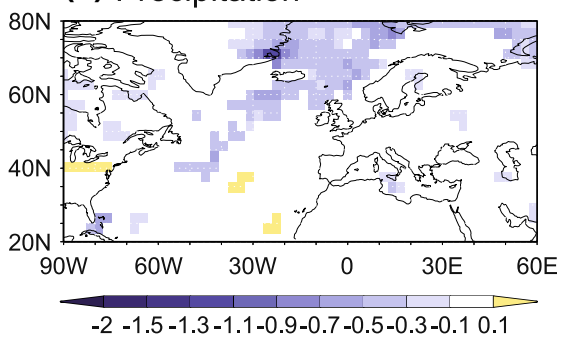

Fig. 3 As in Fig. 2, but for the difference in a clear-sky OLR $\left[\mathrm{Wm}^{-2}\right]$, b LW radiation absorbed in the atmosphere $\left[\mathrm{Wm}{ }^{-2}\right]$ and $\mathbf{c}$ total precipitation $\left[\mathrm{mm} \mathrm{day}^{-1}\right]$ 
warming of the oceans. The colder atmosphere in the GSD simulation, however, has less capacity to hold moisture. This reduces the mean water vapor column compared to GHG over the Northern parts of the North Atlantic Ocean (not shown). The (GSD-GHG) precipitation patterns for (2021-2050) show significant negative values in these regions as well (Fig. 3c). Here the cooling effect is largest. The negative values denote a significantly smaller precipitation increase in a warmer climate when anthropogenic sulfate aerosol is considered additionally.

\subsection{North Atlantic Oscillation}

The North Atlantic Oscillation (NAO) is one of the most dominant modes of natural climate variability. It has strong effects on weather and climate in the North Atlantic region. The term 'NAO pattern' has been given to the observed recurring pressure anomaly pattern due to a large-scale seesaw in atmospheric mass between the Azores high and the Icelandic low. The NAO index describes the large-scale atmospheric pressure difference between these regions and is commonly used as an indicator for the strength of the westerlies over the eastern North Atlantic. In its positive phase it is associated with a deeper than normal Icelandic low and a stronger than normal Azores high. As a consequence for Europe, enhanced westerlies bring more warm moist air over the continent, resulting in warmer and wetter than average winter conditions in northwestern Europe. Southern Europe tends then to be colder and drier. In its negative phase weaker mean westerlies with corresponding colder and drier northwestern European winters occur, and warm and wet conditions are dominating in the South. It is apparent that the NAO is controlling the position of the cyclone tracks and meteorological variables such as temperature, precipitation and surface wind speed. Over the past years numerous scientific NAO-related articles have been published. For more information about this mode of variability we refer to the basic publications (e.g. Hurrell et al. 2003; Dickson et al. 2000) and the references cited therein. There is public concern if there will be a change in the occurrence of cyclones with global warming associated with extreme NAO or heavy storm events. In this study we are interested in whether the direct aerosol effect has the potential to influence the structure and temporal evolution of the NAO and the mean position and density of the cyclone tracks.

The temporal evolution of the NAO pattern can be characterized by different kinds of NAO indices. One method to determine NAO pattern and index is the widely used empirical orthogonal function (EOF) analysis-or principal component (PC)-technique. Here the NAO pattern is identified from the eigenvectors of the crosscorrelation matrix, computed e.g. from the MSLP anomalies at every grid point in the model domain. The NAO index is then represented by the PC time series corresponding to the leading EOF. Following this method, Stephenson and Pavan (2003) validated the NAO in the CTL simulation investigated here together with 16 other AOGCMs in comparison to observations. They defined as NAO index the leading PC of the surface temperature anomalies, taking advantage of the more robust signature in surface temperature to define this phenomenon. They demonstrated that ECHAM4-OPYC-as 12 other AOGCMs-is able to capture the NAO pattern based on observations. However, they showed also that ECHAM4/ OPYC, as some other models, overestimates the observed weak anti-correlation between the NAO temperature index and ENSO.

By applying the EOF technique to MSLP data, we determine the NAO patterns from ECMWF reanalysis data ERA-40 (for the years 1959-2001; Uppala et al. 2005) in comparison to the CTL simulation (1990 conditions) as shown in Fig. 4a, d. The same technique is applied also to the GHG and GSD simulations for the periods (1861-1990) and (2021-2050) (Fig. 4b, c, e, f). All panels in Fig. 4 show the same characteristic features of the typical NAO pattern: the two distinct centers of action located near Iceland and between the Azores and the Bay of Biscay. The NAO pattern for CTL has a somewhat larger amplitude than ERA-40 near Iceland. Generally, the NAO in the CTL simulation shows a greater influence over North Europe than is reflected by the reanalysis data. The ERA- 40 pattern explains the largest amount of total variance (52\%), compared with the modeled patterns. If we consider the panels for the period (1861-1990) (Fig. 4b, c), it can be seen that the GSD NAO pattern exhibits a greater extension to the East and suggests a different position of the jet stream than the GHG pattern for this period. It matches better the ERA40 pattern than GHG, since GHG shows a somewhat too weak amplitude of the Azores high. If we compare the GHG and GSD patterns projected into the future period (2021-2050) (Fig. 4e, f), it becomes apparent that in GHG this amplitude is even more weakened (Fig. 4e), whereas the subtropical high pressure region is most pronounced and elongated for the GSD simulation in the future period (Fig. 4f).

The associated PC time series, which represent the NAO indices, are shown in Fig. 5 for ERA-40 (1959-2001), the CTL simulation (300 years), and the GHG as well as GSD simulation for the entire period (1861-2050). Each NAO time series is standardized by subtraction of its mean and division by its standard deviation $\sigma$. The modeled NAO indices generally show a strong year-to-year variability. The known upward trend in the observed NAO index can be seen in the ERA-40 data. Since 1980, the NAO has remained mostly in a positive phase. If we consider the 
(a) ERA-40 (1959-2001) $\mathbf{5 2 \%}$
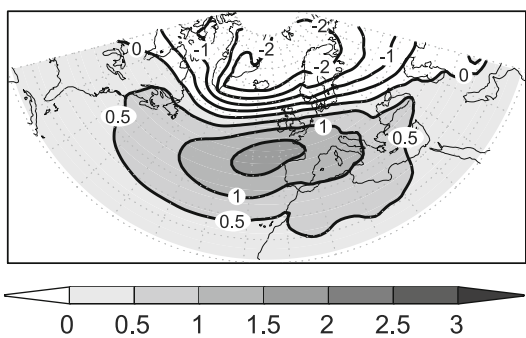

(d) CTL
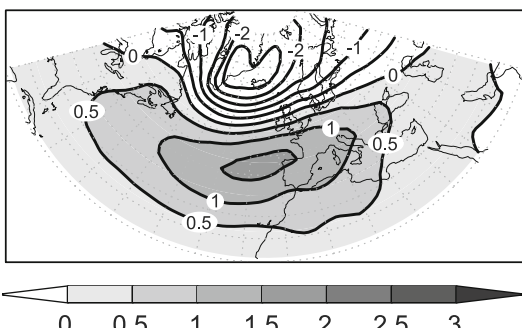

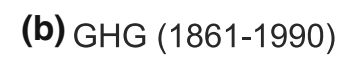

$39 \%$

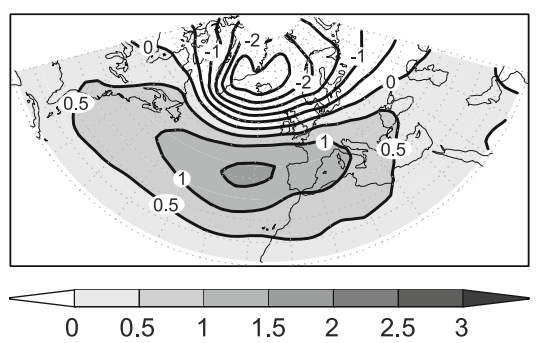

(e) GHG (2021-2050)

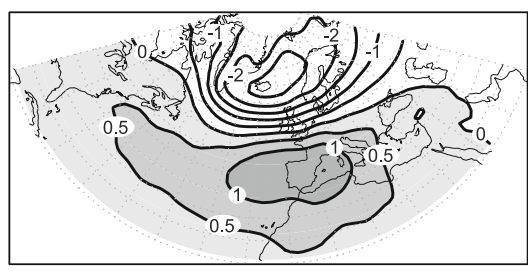

$\leftarrow$
Fig. 4 Leading EOFs of North Atlantic sea level pressure anomalies based on winter (DJFM) means of a ERA-40 (1959-2001) reanalysis, b GHG simulation (1861-1990), c GSD simulation (1861-1990), d CTL simulation (1990 conditions, 300 years), e GHG simulation (c) GSD (1861-1990) $\quad 40 \%$

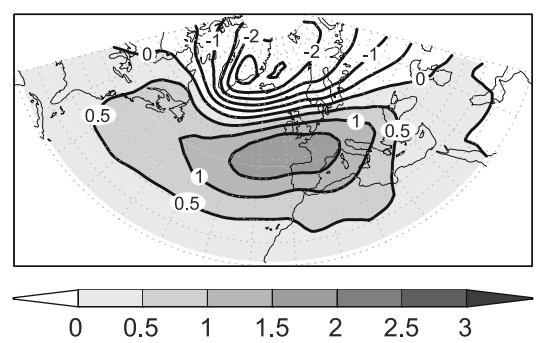

(f) GSD (2021-2050)

$44 \%$

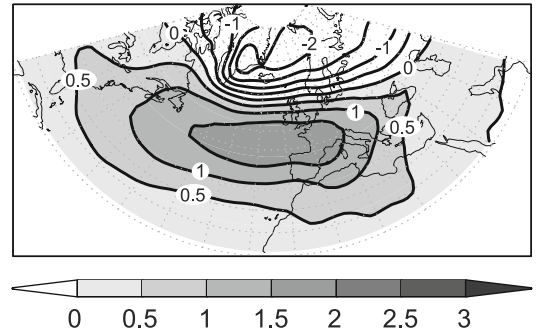

(2021-2050), f GSD simulation (2021-2050). Contour interval is $0.5[\mathrm{hPa}]$, positive values are shaded. The percentage of the total variance accounted by these modes is indicated in the headlines

(a) ERA-40

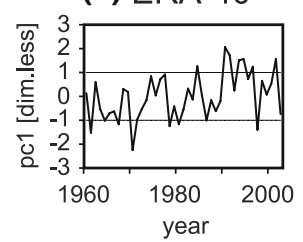

Fig. 5 NAO indices associated to the patterns in Fig. 4 for a ERA-40 (1959-2001) reanalysis, b CTL simulation (300 years), c GHG simulation (1861-2050), and d GSD simulation (1861-2050). The

simulations over the whole period (1861-2050), no significant linear trend can be identified in either NAO index for GHG and GSD. This can be seen easily already by visual inspection. The trend lines are nearly in accordance with the zero lines (not shown). Also the non-linear trends, obtained according to Ulbrich and Christoph (1999) from quadratic curve fitting, are not significant in that sense that they do not exceed the level defined by $1 \sigma$, at least until year 2050. Comparing the unstandardized time series (not shown) with each other, we find that both variabilities are quite similar $\left(\sigma_{\mathrm{GHG}}=1.70, \sigma_{\mathrm{GSD}}=1.74\right)$. However, both simulations differ concerning the number of extreme NAO events, which we define as winters with NAO indices above $\left(\mathrm{NAO}^{+}\right)$and below $1 \sigma\left(\mathrm{NAO}^{-}\right)$. The numbers of 'extreme' NAO events occurring per century are shown in Fig. 6 for the different simulations and periods. In the undisturbed CTL simulation, the occurrence of $\mathrm{NAO}^{+}$and (c) $\mathrm{GHG}$

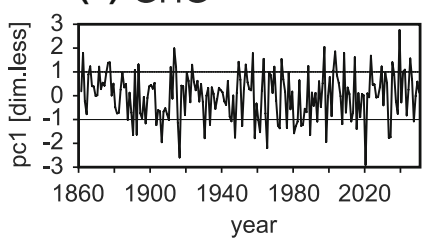

(d) GSD

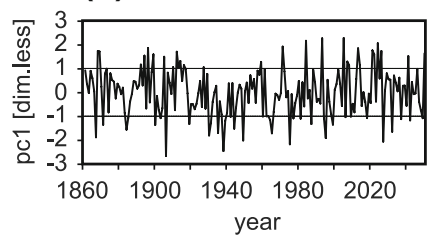

dimensionless time series are standardized to have unit variance. The horizontal lines indicate $\pm 1 \sigma$

$\mathrm{NAO}^{-}$is well balanced $\left(16 \mathrm{NAO}^{+}, 17 \mathrm{NAO}^{-}\right)$. CTL exhibits more $\mathrm{NAO}^{+}$events, but less $\mathrm{NAO}^{-}$events than in GHG for (1861-1990) $\left(14 \mathrm{NAO}^{+}, 21 \mathrm{NAO}^{-}\right)$, respectively than in GSD for (1861-1990) $\left(12 \mathrm{NAO}^{+}, 19 \mathrm{NAO}^{-}\right)$. Projecting into the future period (2021-2050), the number of $\mathrm{NAO}^{+}$increases strongly in $\mathrm{GHG}$, whereas the number for $\mathrm{NAO}^{-}$decreases $\left(23 \mathrm{NAO}^{+}, 10 \mathrm{NAO}^{-}\right)$. By additionally considering the counteracting cooling of the sulfate aerosol, this strong increase, respectively decrease, is dampened $\left(20 \mathrm{NAO}^{+}, 17 \mathrm{NAO}^{-}\right)$, working towards a balance between both cases as we have found in the undisturbed CTL simulation.

\subsection{NAO correlation patterns}

In the previous section we have defined the NAO in terms of pressure. However, as mentioned before, the NAO is 




Fig. 6 Number of extreme NAO events per century for the different simulations and different time periods. $\mathrm{NAO}^{+}\left(\mathrm{NAO}^{-}\right)$denotes NAO index above (below) $1 \sigma$

also strongly related to the mid-latitude variations in the seasonal means of different meteorological variables such as near surface temperature, SLP, and hydrological quantities. It accounts for much of their variability on interannual and longer time scales over the Euro-Atlantic region. This leads us to investigate the correlation between the pressure based NAO index and the near surface temperature, as well as between NAO and precipitation, for the different time periods. We are interested in how the modeled correlation patterns look like in the present climate and in a warmer climate with and without the influence of the sulfate aerosol. For an evaluation of the model's skill in generating the present correlation patterns, we first compare model results with correlation maps based on observed datasets (from Osborn et al. 1999). Here the observational temperature data, a composition of SST anomalies and $1.5 \mathrm{~m}$ air temperature anomalies over land, were derived from instrumental measurements on a $53 \times 53$ grid box basis. They cover the period 1873-1995. The observational precipitation data set, also on a $53 \times 53$ grid box basis, contains data from 1900 to 1995 for land areas only, derived from rain-gauge measurements. For the determination of the observed NAO index (DJFM) Osborn et al. (1999) used two time series of station pressure. The index had been calculated by the absolute pressure difference between Gibraltar and southwest Iceland. For more details we refer to their above-mentioned publication.

Figures 7 and 8 show the spatial correlation patterns based on observations and the simulations for the different time periods. Figures $7 \mathrm{a}$ and $8 \mathrm{a}$ (which are adopted from Osborn et al. 1999) show correlations as observed between the normalized NAO index and local near surface temperature, respectively local precipitation. The patterns show the northern hemispheric 'spatial signature' of the NAO. Generally, in the case of a positive NAO index, positive correlations indicate that the area is wetter or warmer than normal; negative correlations represent an area drier or colder than normal. Conditions are reversed in the case of a negative NAO index. No correlation means the area is unaffected by the NAO. In positive NAO phases, more and strong winter storms are crossing the Atlantic Ocean on a track shifted to the north. Hence, mean warm and wet winter climate in central and northern Europe is observed, whereas cold and dry climate conditions prevail in the Mediterranean, northern Africa and over the Arabian Peninsula. On the other hand, a positive NAO index is also associated with more frequent, cold dry air outbreaks from Labrador. Thus, the climate is cold and dry over northern Canada and Greenland, but warm and wet for the eastern American continent. (Figs. 7a, 8a) For low NAO phases, these climate conditions are reversed. It is obvious that especially the NAO-temperature correlation pattern is dominated by a large-scale quadrupole pattern with centers over Northwest Europe and the northwest Atlantic characterizing the northern seesaw. The centers over the United States and the Middle East are reflecting the southern seesaw. The relationship between NAO and temperature is strongest over Southern Scandinavia and Finland. The correlations based on the model simulations (Figs. 7 and $8 \mathrm{~b}-\mathrm{f}$, respectively) are computed at each grid point of the Northern Hemisphere $\left(20-80^{\circ} \mathrm{N}\right)$. The model results are statistically significant at the $95 \%$ level according to a Student's $t$ test. Areas with no significant correlations are masked out after having computed the isolines.

At first we analyze the spatial signature of the NAO with respect to temperature in Fig. 7. In accordance with Stephenson and Pavan (2003) both seesaws are described quite realistic by the CTL simulation (Fig. 7d). The observed seesaws are captured as well in the simulations GHG and GSD (Fig. 7b, c) for data covering the time period (1861-1990). No striking difference concerning the structure between the CTL and GHG nor the GSD pattern is found. There are, however, differences in magnitude. For the GSD simulation (1861-1990) we get higher positive correlations compared to GHG (1861-1990) especially over eastern North America and Russia. Thus they are in better accordance with the magnitudes in the CTL pattern than GHG. The corresponding patterns in a warmer climate (Fig. 7e, f) illustrate that the relationship NAO-temperature varies significantly depending on the time period. The comparison of Fig. 7b with and Fig. 7e shows that with increase of anthropogenic greenhouse gas concentrations correlations increase slightly in the main centers of NAO influence over the North Atlantic Ocean, Europe and North Africa. On the other hand, large areas of significant NAO- 
(a) Observations (1873-1995)



(d) CTL

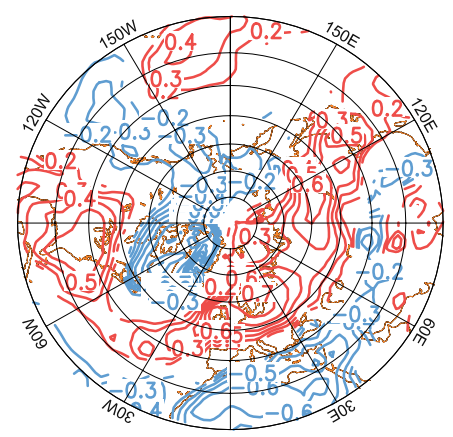

(b) GHG (1861-1990)

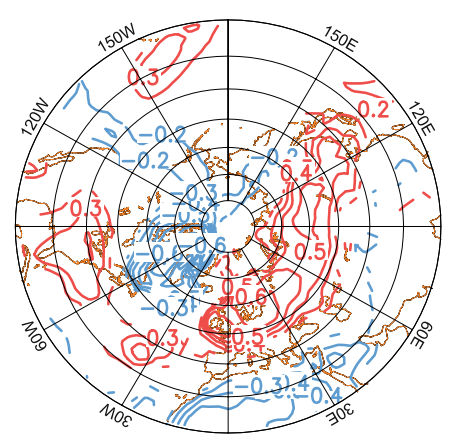

(e) GHG (2021-2050)

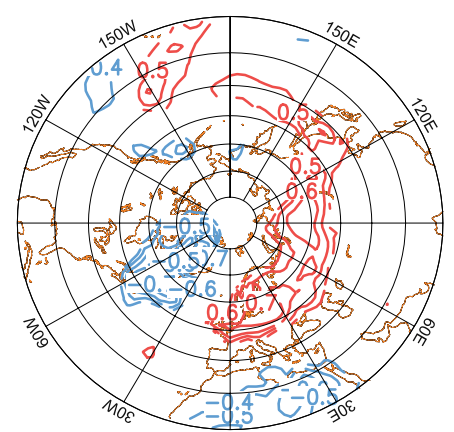

(c) GSD (1861-1990)

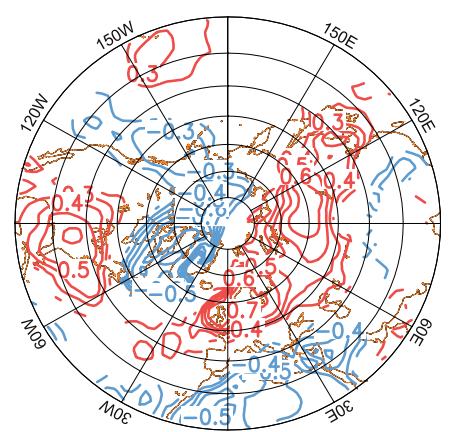

(f) GSD (2021-2050)

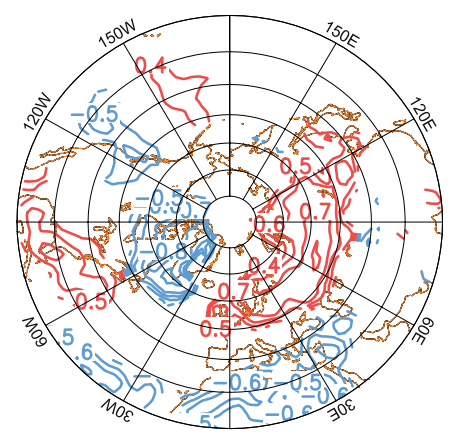

Fig. 7 Correlation map of winter (DJFM) mean near surface temperature with the normalised NAO SLP index. a As observed (1873-1995, from Osborn et al. 1999), b in GHG simulation (18611990), $\mathbf{c}$ in GSD simulation (1861-1990), $\mathbf{d}$ in CTL simulation (1990 conditions, 300 years), $\mathbf{e}$ in GHG simulation (2021-2050), $\mathbf{f}$ in GSD

temperature correlation as observed in the current climate have disappeared (over eastern America and the central North Atlantic as part of the southern seesaw, and over parts of the Middle East as well, Fig. 7e). For GSD (20212050), however, the NAO influence over Eastern North America remains, although there is a reduction in extent and strength compared with GSD (1861-1990) (Fig. 7c, f). Generally, the centers of NAO influence show a larger extent and strength for GSD (2021-2050), where the future warming is attenuated due to the influence of the sulfate aerosol, compared with GHG (2021-2050), where future warming is larger due to the lack of the aerosol. This is in accordance with the difference in spatial structure of the southern center in the corresponding NAO patterns shown in Fig. 5e, $f$ for GHG (2021-2050) and GSD (2021-2050).

The comparison of the modeled NAO-precipitation correlation patterns with observations is restricted, since the latter cover land areas only. The observations show that north of $50^{\circ} \mathrm{N}$ positive NAO values are associated with a precipitation increase, whereas over the Mediterranean region correlations are negative. This is reflected also in the modeled patterns for GHG (1861-1990), GSD (18611990) and CTL (Fig. 8b-d). A comparison of the patterns simulation (2021-2050). Positive isolines are depicted in red, negative isolines in blue. Isoline values are $\pm(0.1,0.2,0.3, \ldots, 1)$. In b-f areas where the difference is not statistically significant at the 95\% level are masked white

for the future period with those for (1861-1990) for both GHG and GSD also reveals (as in case for temperature) that the additional consideration of sulfate induces a tendency to higher correlations, respectively anti-correlations, over large areas in the future period, especially over the central North Atlantic Ocean.

\subsection{Baroclinicity and cyclone tracks}

Extratropical synoptic weather systems determine the local day-to-day weather and play an important role in regulating the transport of water, heat and momentum. Thus, we would like to know if the aerosol has an impact on the North Atlantic cyclone tracks. A primary mechanism for the development of extratropical cyclones is the baroclinic instability, the atmospheric potential for forming cyclones. The baroclinicity during the first stages of the cyclogenesis can be quantified in terms of the maximum linear growth rate $\sigma_{\mathrm{BI}}$ of the baroclinic instability (Eady 1949). The socalled Eady growth rate is defined by the ratio of thermal wind to static stability: $\sigma_{\mathrm{BI}}=0.31 \cdot(f / N) \cdot|\partial u / \partial z|$. Here, $f$ is the Coriolis parameter, $\partial u / \partial z$ the vertical wind shear and $N$ the Brunt-Väisälä frequency (Lindzen and Farrell 1980; 
(a) Observations (1900-1995)

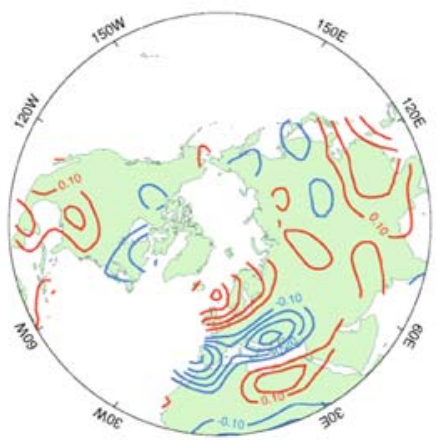

(d) CTL

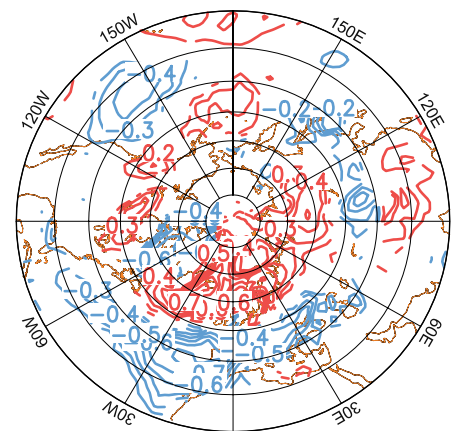

(b) GHG (1861-1990)

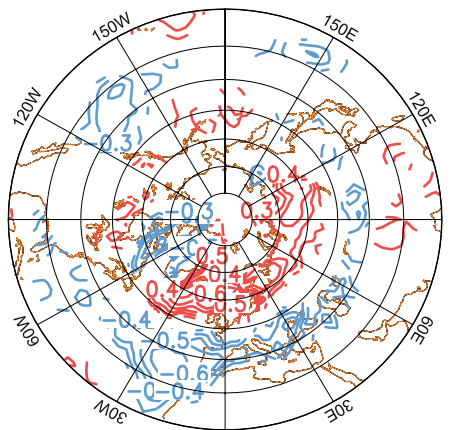

(e) GHG (2021-2050)

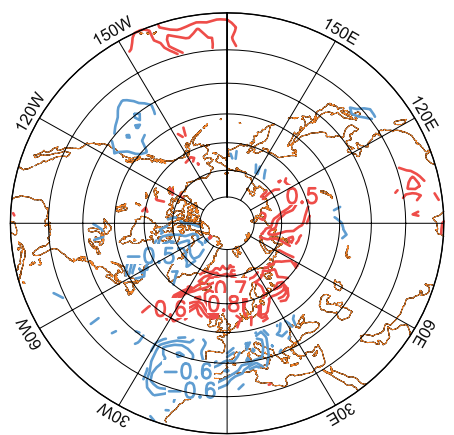

(c) GSD (1861-1990)

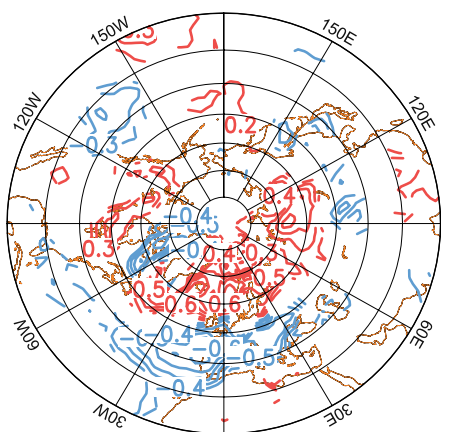

(f) GSD (2021-2050)

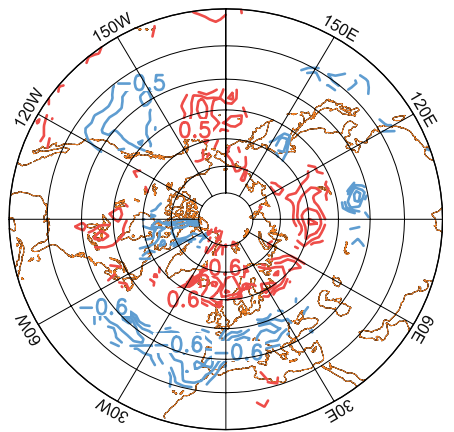

Fig. 8 Correlation maps of winter (DJFM) precipitation with the normalised NAO SLP index. a As observed (1900-1995, but land-only, from Osborn et al. 1999), b-f as in Fig. 7 but for precipitation

Hoskins and Valdes 1990). The Eady growth rate is often referred to as the simplest measure for the baroclinicity of the basic flow in the literature. We use the lower tropospheric maximum Eady growth rate at $775 \mathrm{hPa}$ (i.e. for the layer $700-850 \mathrm{hPa}$ ) as a measure for the atmosphere's potential to produce cyclones. A high growth rate favours a frequent development of cyclones and indicates the region where the jet stream is located.

To evaluate the performance of the model we first compare the baroclinicity as calculated from the reanalysis data with the baroclinicity as simulated for 1990 conditions. Figure 9a shows the climatological maximum Eady growth rate (referred to henceforth as simply 'baroclinicity') for winter from ERA-40 reanalysis data averaged over (1961-1990). Regions of enhanced baroclinicity, i.e. regions of cyclogenesis, can be found south of Nova Scotia extending northeastward to western Europe. Increased baroclinicity is also apparent over North Africa and the Arabian Peninsula. The regions of high baroclinicity are generally in good agreement with the results for the CTL simulation (Fig. 9b), especially over the East coast of North America and the Atlantic Ocean. Some discrepancies can be found over Greenland, the Barents Sea as well as North Africa. The correspondent figure for GHG (19611990) is not shown since it agrees very well with CTL.
The lower panels in Fig. 9 display the track density determined by the method described in Sect. 3.3. As for baroclinicity, the result for GHG (1961-1990) differs only slightly from CTL and thus we show only results for the reanalysis and CTL, which we compare with the upper panels in Fig. 9. The North Atlantic Ocean is a region where new storms intensify or older storms redevelop. Since the cyclones propagate as they develop, they reach maturity further downstream along the cyclone track. Accordingly, regions of maximum track density are not coincident with regions of maximum baroclinicity. The baroclinicity is largest at the beginning of the North Atlantic storm track, off the East coast of North America, where the atmosphere is most unstable due to the strong diabatic heating. The regions with largest track density as found in ERA-40 (Fig. 9c) are depicted in comparison to the enhanced cyclonic activity in CTL (Fig. 9d). The reanalysis shows a band expanding from the east coast of North America via Greenland and Iceland into the Norwegian Sea and Barents Sea, as well as a less pronounced local maximum in the Mediterranean. The comparison reveals fewer cyclones in the CTL simulation as observed in the region of the Great Lakes, near the Denmark Strait, to the west and north of Scandinavia and in the Mediterranean. Maximum track densities occur near Nova Scotia and Newfoundland, in the Davis Strait and in the 
Fig. 9 Upper panels 850$700 \mathrm{hPa}$ maximum Eady growth rate (DJF) $\left[\mathrm{day}^{-1}\right]$ a from ERA40 reanalysis data averaged over 1961-1990, and b for the CTL simulation. Lower panels $\mathbf{c}$ and d as upper panels but for track density [number densities per month per $\left.10^{6} \mathrm{~km}^{2}\right]$. Track density suppression threshold is 0.2 (a) ERA-40 (1961-1990)

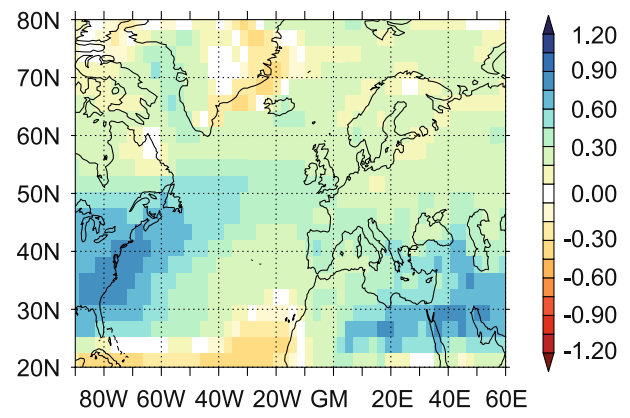

(c) ERA-40 (1961-1990)

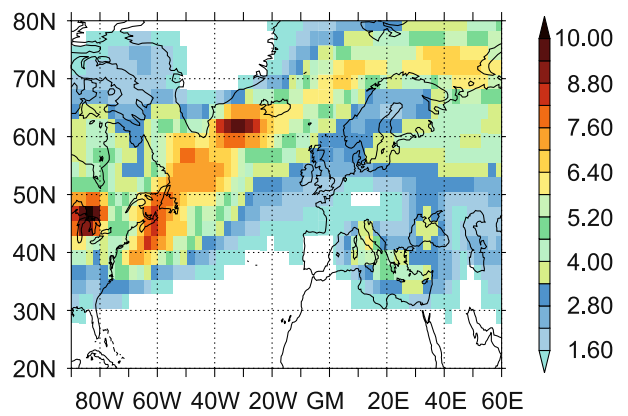

(b) CTL

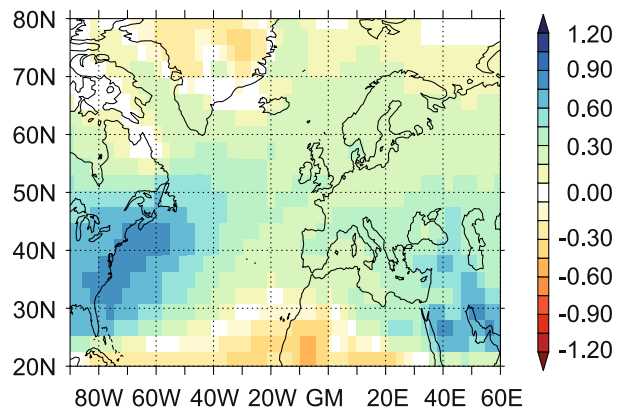

(d) CTL

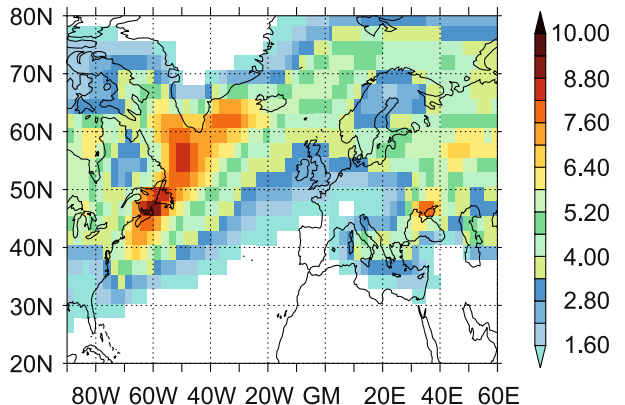

Denmark Strait. On the other hand, more cyclones than in ERA-40 occur around the Caspian Sea and especially over the European part of Russia and near the Black Sea. However, the overall agreement between CTL and ERA-40, especially over the North Atlantic Ocean and Western Europe, gives confidence in the performance of the model and the tracking algorithm (Banse 2008).

Figure 10a, c shows the projected future change in baroclinicity and track density without consideration of the cooling sulfate aerosol. The panels depict the differences in both quantities between (2021-2050) and (1961-1990) in the GHG simulation. Areas of decreased baroclinicity dominate the pattern in Fig. 10a, concentrating in one band from the East coast of North America over the Atlantic Ocean to Southern Europe/North Africa and further to the Northeast to the Caspian Sea. Decreased atmospheric potential to form cyclones can also be found over the Labrador Sea and Greenland Sea and further to the East. The decrease in baroclinicity can be associated with a decrease in the meridional SST gradient under enhanced greenhouse gas concentrations (not shown), since the high latitudes warm more than the lower ones. This can be related to the reduction in track density in Fig. 10c for GHG in a region extending from the British Isles over the Southeast of Europe to eastern Russia-regions located downstream of the regions with largest decreases in baroclinicity. A significant decrease in track density is also apparent along the American coast north of $35^{\circ} \mathrm{N}$ and over Baffin Island. On the other hand, there is a strong significant increase to the east of Greenland and north of $65^{\circ} \mathrm{N}$. The distinct regions with significant negative and positive differences give the overall picture of a poleward transition of the cyclone tracks. However, we obtain large regions in Fig. 10a with insignificant changes, masked in white, instead of a significant increase in baroclinicity related to the regions of increased track density with future warming over the northern North Atlantic, as could be expected.

To find out if the direct aerosol effect has an impact on the simulated cyclone tracks in (2021-2050), we calculate the difference (GSD-GHG) for baroclinicity and track density over this period (Fig. 10b and d). Positive differences in Fig. 10b denote a smaller future decrease in baroclinicity in GSD compared to GHG. Regions with significant differences are found over the Labrador Sea along the East coast of Greenland, north of $65^{\circ} \mathrm{N}$, reaching Finland and Russia. Large differences can be seen also over the Gulf of Mexico extending to the East and over WestAfrica. The sulfate effect on change in track density is shown in Fig. 10d. Here, negative values denote a smaller future increase and positive values a smaller future decrease in track density. Though, after application of the significance test, a smaller increase in track density is found only over some isolated regions over the northern North Atlantic Ocean (Fig. 10d). Areas with significant smaller decreases (positive values) are only found over Baffin Island and over a small region in Russia. Larger areas with significant changes, as we expected to find over Europe or adjacent regions in the South, however, cannot be diagnosed. 
Fig. 10 Upper panels Difference in 850-700 $\mathrm{hPa}$ maximum Eady growth rate (DJF) $\left[10^{-3}\right.$ day $\left.^{-1}\right]$ between a (2021-2050) and (1961-1990) in simulation $\mathrm{GHG}$, and $\mathbf{b}$ difference (GSD-GHG) between both simulations over period (2021-2050). Lower panels $\mathbf{c}$ and $\mathbf{d}$ as upper panels but for track density [number densities per month per $10^{6} \mathrm{~km}^{2}$ ]. Track density suppression threshold is 0.2 . Areas where the difference is not statistically significant at the 95\% level are masked white in all panels (a) GHG (2021-2050)-(1961-1990)

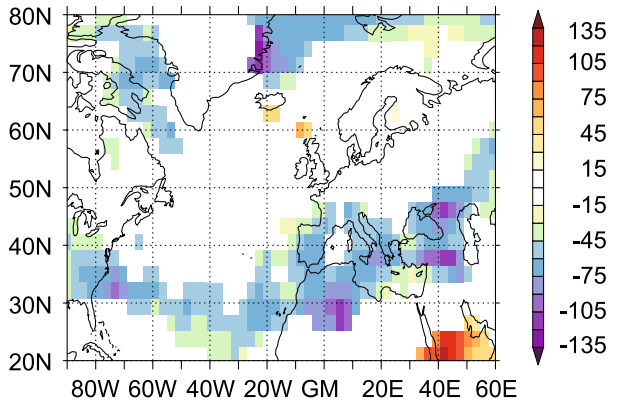

(c) GHG (2021-2050)-(1961-1990)

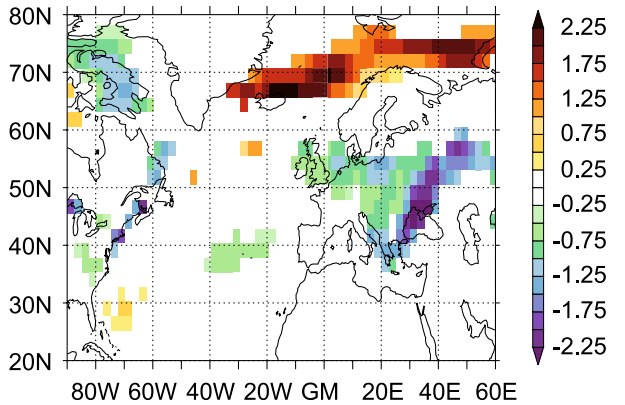

(b) (GSD-GHG) (2021-2050)



(d) (GSD-GHG) (2021-2050)

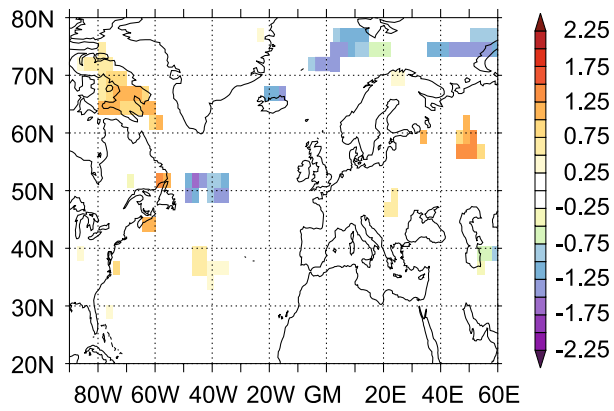

\section{Summary and conclusions}

We know that even though aerosols represent but a marginal fraction of the atmospheric mass, they play an important role in our climate, because they interfere with the radiative transfer through the atmosphere. This implies that the influence of aerosols should not be neglected in climate studies. In this model study we investigate the possible future climate changes due to the impact of the direct clear-sky radiative forcing associated with anthropogenic sulfate aerosol using ECHAM4/ OPYC 3 . We concentrate on the North Atlantic region and the winter season. Two different transient climate simulations including the anthropogenic greenhouse effect are examined. One simulation considers additionally future concentrations of sulfate aerosol. We are linking results concerning temperature, radiative quantities, precipitation, and the NAO with the response in baroclinicity and cyclone track density. In order to evaluate whether our results are statistically significant, we introduce a nonparametric significance test. In doing so, we can avoid the assumptions of normality and comparable variances as required in a Student's $t$ test. Our test is recommended for comparisons of model data when a long control run is available. Generally, we get a similar but weaker future climate response due to the presence of the sulfate. This attenuation is consistent with the findings of Mitchell and Johns (1997), who compared the global response patterns of two AOGCM simulations as well, one forced by greenhouse gas alone, and one including sulfate aerosol.
They focus on the period (2030-2050), where the projected aerosol forcing was maximum, with sulfur dioxide emissions based on the same scenario as here. However, the authors make a simplified approach in representing the backscattering of solar radiation by merely increasing the surface albedo. Consistent to our results, they find a pronounced cooling in boreal winter over the northern midlatitude continents due to sulfate aerosol. It is obvious that the main effect of scattering aerosols is a reduction of the anthropogenic warming due to the significant changes in radiation, although the influence of the long-lived greenhouse gases on the mean temperature overwhelms the partially compensating influence of the short-lived aerosols. We suppose that the differences in temperature and precipitation (as shown in Fig. 2a and 3c) are due initially to the radiation changes and as a consequence, the NAO pattern may change. The poleward extension of the aerosol induced cooling is caused by the difference in snow and sea-ice cover and associated feedbacks in the higher latitudes. If aerosols are neglected, as in simulation GHG, we find that the magnitude of the anthropogenic warming is overestimated. As a consequence a poleward shift of the patterns of NAO related quantities emerge, and a shift in NAO intensity towards a high index. For the investigations of the NAO, we use pressure based EOF analyses. Ulbrich and Christoph (1999) who also investigated the CTL and the GHG simulation, found a northeastward shift of the NAO centers with enhanced greenhouse gas concentrations in the GHG simulation. Though, their NAO index is determined by computing the 
difference between area averaged MSLP anomalies and has been related to the standard deviation of the CTL simulation. Moreover, their model domain is chosen somewhat different $\left(90^{\circ} \mathrm{W}-30^{\circ} \mathrm{E}, 20-90^{\circ} \mathrm{N}\right)$ compared to this study. In accordance to their results, our analysis reveals a future change of the spatial characteristics of the NAO in GHG, namely a shift of the NAO pattern to the East accompanied by an increase of extreme $\mathrm{NAO}^{+}$and a decrease of extreme $\mathrm{NAO}^{-}$events compared to the period (1861-1990). Further we demonstrate that if sulfate is considered additionally, the tendency to an imbalance in extreme NAO cases is reversed, although we see no indication of any dramatic changes like significant future trends in the NAO index in either simulation, if we consider the whole simulation (1861-2050). However, if e.g. only the period (2001-2050) is considered, which includes the strong trend in emissions of anthropogenic greenhouse gases, a positive trend in $\mathrm{GHG}$, but a negative trend in GSD becomes apparent (not shown). This is in accordance with the occurrence of more $\mathrm{NAO}^{+}$than $\mathrm{NAO}^{-}$extremes in the period GHG (2021-2050), which also represents an indication for an upward trend. The correlation patterns of NAO with temperature and precipitation, respectively, for both GHG and GSD, are in good agreement with the observations for the time period up to the present. The outstanding characteristics of the NAO-temperature quadrupole pattern are captured in all simulations. A particular interesting feature is the overall robustness of this pattern, which does not depend crucially on the type of the forcing in our simulations - at least up to the present. The future strong greenhouse gas forcing in GHG, though, tends to reduce the extent of the regions, where the NAO has an influence. This applies in particular to correlations between NAO and temperature. Especially, we find no more influence of the NAO over the southeastern United States, in such a way that positive NAO events are associated with warmer and wetter winters. But if the strong future anthropogenic warming is dampened by the cooling effect of the aerosol, the regions of NAO influence-particularly for temperature-exhibit again a larger areal extent with stronger correlations (Fig. 7f compared to Fig. 7e). This is in accordance with the difference in spatial structure in the corresponding NAO patterns (Fig. 4e, f). Our results lead us to conclude that future NAO changes become more important for the North Atlantic winter climate when the direct aerosol effect in our model is considered additionally, since we find larger regions of influence and a tendency to higher correlations, respectively anti-correlations.

The model is also capable in reproducing the main features of the storm track. The simulated cyclone track density for 'present day' climate is in satisfying agreement with the ERA-40, at least over the North Atlantic
Ocean and Western Europe. Concerning the poleward shift of the cyclone tracks in the simulation without consideration of aerosols, our results agree with many other studies (e.g. Schubert et al. 1998; König et al. 1993; Yin 2005; Bengtsson et al. 2006). There are indications that this shift is attenuated if sulfate is considered additionally, since due to the cooling of the aerosol, there is a smaller decrease in baroclinity in the future climate than in GHG. We expected this to be related to a smaller increase in track density north of $50^{\circ} \mathrm{N}$. However, a significant aerosol impact on the track density can be found only over some relatively small, isolated regions over the northern North Atlantic Ocean. The fact that there is no clear signal implies that the natural variability of the related variables in this region is large.

As the performance of a numerical climate model is always limited, one caveat of this study - and of many other climate studies - is that the results are obtained only by one single model and one realization of each simulation. Moreover, there is some evidence that mechanisms involving the stratosphere can influence the NAO, though the extent of this interaction is still an open question (e.g. Vallis and Gerber 2008, and references cited therein). Furthermore, the direct aerosol forcing represents only one part of the overall aerosol effect. Here we disregard indirect aerosol effects as well as the effects of some major aerosol components such as absorbing carbonaceous aerosols. Still, we consider the present study to be relevant for understanding the North Atlantic climate with increasing anthropogenic warming and simultaneous consideration of scattering aerosol. Our results emphasize the view that changes in the atmospheric aerosol load have the potential to influence large-scale circulation over the North Atlantic. Clearly, this study cannot provide information on climate effects due to the full suite of aerosol components and related processes, which are a subject of our ongoing research. The consideration of indirect aerosol effects is also required in future simulations, in particular to address issues associated with aerosol-cloud interactions.

Acknowledgments This work was funded by the 'Sonderforschungsbereich' (SFB) 512 sponsored by the 'Deutsche Forschungsgemeinschaft' (DFG). We thank E. Roeckner for helpful suggestions. Discussions with S. Kinne and M. Giorgetta were constructive and helpful as well. Furthermore we would like to thank $\mathrm{K}$. Hodges for providing the tracking method and are grateful to $\mathrm{T}$. Osborn for supplying the figures of the correlation patterns based on observations. We also appreciate the help of Norbert Noreiks and Elisabeth Viktor in adapting the figures.

Open Access This article is distributed under the terms of the Creative Commons Attribution Noncommercial License which permits any noncommercial use, distribution, and reproduction in any medium, provided the original author(s) and source are credited. 


\section{References}

Bacher A, Oberhuber JM, Roeckner E (1998) ENSO dynamics and seasonal cycle in the tropical Pacific as simulated by the ECHAM4/OPYC3 coupled general circulation model. Clim Dyn 14:431-450. doi:10.1007/s003820050232

Banse DF (2008) The influence of aerosols on North Atlantic cyclones. PhD thesis, University of Hamburg. Reports on Earth System Science 53, ISSN 1614-1199, Max-Planck-Institute for Meteorology, Hamburg, Germany

Bengtsson L, Hodges KI, Roeckner E (2006) Storm tracks and climate change. J Clim 19:3518-3543. doi:10.1175/JCLI3815.1

Bellouin N, Boucher O, Haywood J, Reddy MS (2005) Global estimate of aerosol direct radiative forcing from satellite measurements. Nature 438:1138-1141. doi:10.1038/nature 04348

Carnell RE, Senior CA (1998) Changes in midlatitude variability due to increasing greenhouse gases and sulfate aerosols. Clim Dyn 14:369-383. doi:10.1007/s003820050229

Dickson RR, Osborn TJ, Hurrell JW, Meincke J, Blindheim J, Adlandsvik B et al (2000) The Arctic Ocean response to the North Atlantic Oscillation. J Clim 13:2671-2696. doi :10.1175/ 1520-0442(2000)013<2671:TAORTT $>2.0 . \mathrm{CO} ; 2$

Eady ET (1949) Long waves and cyclone waves. Tellus 1:33-52

Feichter J, Kjellström E, Rohde H, Dentener F, Lelieveld J, Roelofs GJ (1996) Simulation of the tropospheric sulfur cycle in a global climate model. Atmos Environ 30:1693-1707. doi:10.1016/ 1352-2310(95)00394-0

Feichter J, Lohmann U, Schult I (1997) The atmospheric sulfur cycle and its impact on the short wave radiation. Clim Dyn 13:235246. doi: $10.1007 / \mathrm{s} 003820050163$

Forster PM et al (2007) Changes in atmospheric constituents and in radiatve forcing. In: Solomon S, Qin D, Manning M, Chen Z, Marquis M, Averyt KB, Tignor M, Miller HL (eds) Climate change 2007: the physical science basis. Contribution of working group I to the fourth assessment report of the intergovernmental panel on climate change. Cambridge University Press, Cambridge

Hodges KI (1999) Adaptive constraints for feature tracking. Mon Weather Rev 127:1362-1373. doi :10.1175/1520-0493(1999) $127<1362$ :ACFFT $>2.0 . \mathrm{CO} ; 2$

Hoskins BJ, Valdes PJ (1990) On the existence of storm-tracks. J Atmos Sci 47:1854-1864. doi :10.1175/1520-0469(1990)047< 1854:OTEOST $>2.0 . \mathrm{CO} ; 2$

Hoskins BJ, Hodges KI (2002) New perspectives on the northern hemisphere winter storm tracks. J Atmos Sci 59:1041-1061. doi :10.1175/1520-0469(2002)059<1041:NPOTNH>2.0.CO;2

Houghton JT, Callander BA, Varney SK (eds) (1992) Climate change 1992: the supplementary report to the IPCC scientific assessment. Cambridge University Press, Cambridge

Hurrell JW, Kushnir Y, Ottersen G, Visbeck M (2003) An overview of the North Atlantic Oscillation. In: Hurrell JW, Kushnir Y, Ottersen G, Visbeck M (eds) The North Atlantic Oscillation: Climatic significance and environmental impact. Geophysical Monographs Series, vol 134. pp 1-35

IPCC (1990) Intergovernmental panel on climate change. In: Houghton JT, Jenkins GJ, Ephraums JJ (eds) Scientific assessment of climate change. Cambridge University Press, Cambridge, $365 \mathrm{pp}$

Knippertz P, Ulbrich U, Speth P (2000) Changing cyclones and surface wind speeds over the North Atlantic and Europe in a transient GHG experiment. Clim Res 15:109-122. doi:10.3354/ cr015109
König W, Sausen R, Sielmann F (1993) Objective identification of cyclones in GCM simulations. J Clim 6:2217-2231. doi :10.1175/1520-0442(1993)006<2217:OIOCIG >2.0.CO;2

Lindzen RS, Farrell B (1980) A simple approximate result for the maximum growth rate of baroclinic instabilities. J Atmos Sci 37:1648-1654. doi :10.1175/1520-0469(1980)037<1648: ASARFT $>2.0 . \mathrm{CO} ; 2$

Mitchell JFB, Johns TC (1997) On modification of global warming by sulfate aerosols. J Clim 10:245-267. doi :10.1175/1520-0442 (1997)010<0245:OMOGWB > 2.0.CO;2

Nakicenovic N, Swart R (eds) (2000) Special Report on Emissions Scenarios, Cambridge University Press, Cambridge, UK

Oberhuber JM (1993) Simulation of the Atlantic circulation with a coupled sea ice mixed layer-isopycnal general circulation model. Part I: model description. J Phys Oceanogr 23:808-829. doi :10.1175/1520-0485(1993)023<0808:SOTACW >2.0.CO;2

Osborn TJ, Briffa KR, Tett SFB, Jones PD, Trigo RM (1999) Evaluation of the North Atlantic Oscillation as simulated by a coupled climate model. Clim Dyn 15:685-702. doi:10.1007/ s003820050310

Raval A, Ramanathan V (1989) Observational determination of the greenhouse effect. Nature 342:758-762. doi:10.1038/342758a0

Reader MC, Boer GJ (1998) The modification of greenhouse gas warming by the direct effect of sulfate aerosols. Clim Dyn 14:593-607. doi:10.1007/s003820050243

Roeckner E, Arpe K, Bengtsson L, Christoph M, Claussen M, Duemenil L et al (1996a) The atmospheric general circulation model ECHAM-4: model description and simulation of presentday climate. MPI Report No. 218, Max-Planck-Institute for Meteorology, Hamburg

Roeckner E, Oberhuber JM, Bacher A, Christoph M, Kirchner I (1996b) ENSO variability and atmospheric response in a global coupled atmosphere-ocean GCM. Clim Dyn 12:737-754. doi: 10.1007/s003820050140

Roeckner E, Bengtsson L, Feichter J, Lelieveld J, Rodhe H (1999) Transient climate change simulations with a coupled atmosphere-ocean GCM including the tropospheric sulfur cycle. J Clim 12:3004-3032. doi :10.1175/1520-0442(1999)012<3004: TCCSWA $>2.0 . \mathrm{CO} ; 2$

Schubert M, Perlwitz Ja, Blender R, Fraedrich K, Lunkeit F (1998) North Atlantic cyclones in CO2-induced warm climate simulations: frequency, intensity, and tracks. Clim Dyn 14:827-837. doi:10.1007/s003820050258

Stephenson DB, Pavan V (2003) The North Atlantic Oscillation in coupled climate models: CMIP1 evaluation. Clim Dyn 20:381399

Ulbrich U, Christoph M (1999) A shift of the NAO and increasing storm track activity over Europe due to anthropogenic greenhouse gas forcing. Clim Dyn 15:551-559. doi:10.1007/ s003820050299

Uppala SM et al (2005) The ERA-40 re-analysis. Quart J Roy Meteor Soc 131B:2961-3012

Vallis GK, Gerber EP (2008) Local and hemispheric dynamics of the North Atlantic Oscillation, annular patterns and the zonal index. Dyn Atmos Oceans 44:184-212. doi:10.1016/j.dynatmoce. 2007.04.003

Yin JH (2005) A consistent poleward shift of the storm tracks in simulations of $21 \mathrm{st}$ century climate. Geophys Res Lett 32:L18701. doi:10.1029/2005GL023684

Zwiers FW, von Storch H (1995) Taking serial correlation into account in tests of the mean. J Clim 8:336-351. doi :10.1175/ 1520-0442(1995)008<0336:TSCIAI $>2.0$. CO;2 